\title{
Mountain Lions of the Black Hills: History and Ecology
}

By Jonathan A. Jenks. 2018. Johns Hopkins University Press. 160 pages, 75.00 USD, Cloth or E-book.

I have always had a childhood fascination with Mountain Lions (Puma concolor) and a recent narrative I read of a lion travelling from South Dakota to Connecticut got me very interested in learning more about its origins (Way 2017). And so, it was with good fortune that I was able to find it here with Mountain Lions

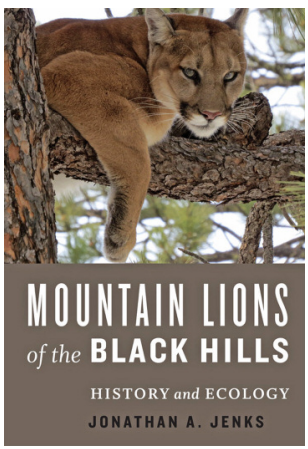
of the Black Hills. The book was an enjoyable read and is a valuable contribution to North America's predatory fauna. Mountain Lion is a cat with many names: Cougar, Puma, Catamount, Panther, and Deer Tiger, among others. Their large range once included virtually all the lower 48 United States from coast to coast, but by the 1960s they were reduced to small populations in the western United States and a token population in south Florida. In Mountain Lions of the Black Hills, author Jonathan Jenks describes his research team's experiences and findings from over 200 of these amazing animals, radio-tracked as they returned to a portion of the northern Great Plains in western South Dakota.

Jenks has an easy-to-read style where each chapter is written like a stand-alone scientific manuscript with a complete Literature Cited section at the end. Each bibliography cites peer-reviewed articles and graduate theses/dissertations, many from his own students.
However, chapters contain simplified enough language to make it readable for the layman and each chapter smoothly flows from one to another as he reports on Mountain Lion ecology, characteristics (e.g., body size and distribution), diet, population dynamics, disease ecology, nutrition, behaviour, and genetics. I particularly liked the sections on dispersal (e.g., pages 57-59) showing how far young Mountain Lions can travel when they leave their mother's territory. Jenks provides very interesting discussion on how that population of lions is connected to others in Wyoming, Colorado, and North Dakota.

Jenks explores a population that was just recolonizing the Black Hills in the late 1990s yet quickly saturated the area within about 10 years. His research examined the impact of a changing prey base on population growth then decline as lions went from a protected species to having an established hunting season set on the cats. A theme of Jenks' prose is figuring out how to balance conserving Mountain Lions with the needs of humans.

I found the book to be useful and a great reference for the species as it slowly expands its range eastward, reclaiming territory that had been lost within the past $100-200$ years. It is easy to find key information on the species, such as territory sizes for males $\left(300+\mathrm{km}^{2}\right)$ and females $\left(66-198 \mathrm{~km}^{2}\right.$ ), body weights of males (averaging $130-150$ pounds, 59-68 kg) and females (90 pounds, $41 \mathrm{~kg}$ ), litter sizes (averaging $3+$ ), age of dispersal (a relatively young 15 months of age), and population size in the Black Hills (150-250). The book is only 160 pages yet has 57 black and white photos and 
15 graphs/tables. I loved all the pictures and thought that it complemented the text perfectly. In fact, I wish more scientifically-oriented books were like this: simple to read, containing concise information, and wellillustrated!

Jenks also explored people's evolving perceptions of Mountain Lions and I found that chapter (8) interesting in a few respects. While I enjoyed the book and thought it was well done, I was troubled by the incessant use throughout of the euphemistic word "harvest" (Johns and Dellasalla 2017) and a total lack of discussion about the ethics of killing a sentient large carnivore (Vuchetich and Nelson 2014). Abundant research indicates carnivores are ecologically important, and are social, sentient, family-oriented animals which regulate their own numbers by defending territories (Eisenberg 2014). Sociological research has consistently demonstrated society's decreasing support of lethal control and trophy hunting, especially regarding carnivores (Jackman and Way 2018). So, it was of interest to me that the main findings from Chapter 8 - that sociological research supported hunting Mountain Lions in South Dakota - are from government reports which had not apparently experienced peer review. I can't help but think that a pro-hunting stance, which all of these government agencies have, may have biased these documents. Given all of the great data presented throughout the book, Jenks' team could've designed a scientifically rigorous hunting season using similar data and methods as described in Washington State, whereby "harvest thresholds" were established in which no more than $14 \%$ of the estimated density of adult resident Mountain Lions could be killed by hunters in relatively small areas to prevent localized over-harvest (see Beausoleil et al. 2013). This provision allows some human recreational use of carnivores, but at a level that should not upset the natural social organization, population stability, or immigration of transient Mountain Lions, and at a level that results in low mortality of adult residents. This protection threshold is particularly important given the relatively isolated nature of the population in the Black Hills. Conversely, it appears that the state of South Dakota just willy-nilly picked "quotas" not based on science but rather on perceived public opinion starting with conservative harvests in 2005 and moving to reduce the population in a short amount of time ( $\sim$ five years). While Jenks does an admiral job documenting how the population stayed genetically healthy, I couldn't help but think of how carnivore hunting generally favours biased or outdated research over the best available independent science (Artelle et al. 2018; Karns et al. 2018).

Overall, this is a valuable book. The illustrations make it a valuable reference for wildlife enthusiasts. It was well written with just a few minor errors. The only thing that perplexed me was the high price for a seemingly simple black and white hardcover book. For the life of me, I cannot fathom why it was \$75 USD when it could probably be $\$ 10$ USD when printed with a softcover. Otherwise, I can't read enough about Mountain Lions and other large carnivores and dream of the day when a similar type of book is written on a recovered Mountain Lion population(s) here in the northeast United States where I reside!

\section{Literature Cited}

Artelle, K.A., J.D. Reynolds, A. Treves, J.C. Walsh, P.C. Paquet, and C.T. Darimont. 2018. Hallmarks of science missing from North American wildlife management. Science Advances 4(3): eaao0167. https://doi.org/10.1126/sciadv.aao0167

Beausoleil, R.A., G.M. Koehler, B.T. Maletzke, B.N. Kertson, and R.B. Wielgus. 2013. Research to regulation: Cougar social behavior as a guide for management. Wildlife Society Bulletin 37: 680688. https://doi.org/10.1002/wsb.299

Eisenberg, C. 2014. The Carnivore Way: Coexisting with and Conserving North America's Predators. Island Press, Washington, DC, USA.

Jackman, J.L., and J.G. Way. 2018. Once I found out: awareness of and attitudes toward coyote hunting policies in Massachusetts. Human Dimensions of Wildlife 23: 187-195. https://doi.org/10. 1080/10871209.2017.1397824

Johns, D., and D.A. Dellasalla. 2017. Caring, killing, euphemism and George Orwell: how language choice undercuts our mission. Biological Conservation 211: 174-176. https://doi.org/10.1016/j.bio con.2017.03.030

Karns, G.R., A. Heeren, E.L. Toman, R.S. Wilson, H.K. Szarek, and J.T. Bruskotter. 2018. Should grizzly bears be hunted or protected? Social and organizational affiliations influence scientific judgments. Canadian Wildlife Biology \& Management 7: 18-30.

Vuchetich, J., and M.P. Nelson. 2014. Wolf hunting and the ethics of predator control. Oxford Handbooks Online 1-15. https://doi.org/ 10.1093/oxfordhb/9780199927142.013.007

Way, J.G. 2017. [Book Review] Heart of a Lion: A Lone Cat's Walk Across America. Canadian Field Naturalist 131: 82-84. https:// doi.org/10.22621/cfn.v131i1.1972

JONATHAN (JON) WAY

Eastern Coyote/Coywolf Research, Osterville, MA, USA 